\title{
Hypertriglyceridemic Rats Fed High Fat Diet as a Model of Metabolic Syndrome
}

\section{B. KAPRINAY ${ }^{1,2}$, B. LIPTÁK ${ }^{1,2}$, L. SLOVÁK ${ }^{1,2}$, K. ŠVÍK $^{1}$, V. KNEZL ${ }^{1}$, R. SOTNÍKOVÁ ${ }^{1}$, Z. GÁSPÁROVÁ ${ }^{1}$}

${ }^{1}$ Institute of Experimental Pharmacology and Toxicology, Slovak Academy of Sciences, Bratislava, Slovak Republic, ${ }^{2}$ Department of Pharmacology, Jessenius Faculty of Medicine, Comenius University, Martin, Slovak Republic

Received September 12, 2016

Accepted October 26, 2016

\begin{abstract}
Summary
People with metabolic syndrome have higher risk of cardiovascular diseases then those without. The aim of the work was to investigate whether high fat diet administered to Prague hereditary hypertriglyceridemic (HTG) rats can induce signs of metabolic syndrome (MetS). Our results showed that HTG rats fed high fat diet (HTGch) had disturbed glucose metabolism and also lipid metabolism - increased serum triacylglycerols (TAG), total cholesterol (Ch), low-density lipoprotein-Ch (LDL-Ch), and decreased high-density lipoprotein-Ch (HDL-Ch). Their livers proved markers of developing steatosis. Moreover, HTGch had increased blood pressure, yet the vascular endothelium was not significantly damaged. All these changes were accompanied with oxidative stress and tissue damage identified as increased liver concentrations of thiobarbituric acid reactive substances (TBARS) and activity of the lysosomal enzyme $\mathrm{N}$-acetyl-D-glucosaminidase (NAGA). We assume that the model used may be suitable for the study of MetS with no evidence of obesity. Prolongation of the high fat diet duration might have a major impact on all parameters tested, especially on vascular endothelial function.
\end{abstract}

\section{Key words}

Metabolic syndrome • Rat model • Hypertriglyceridemic rats

\section{Corresponding author}

B. Kaprinay, Institute of Experimental Pharmacology and Toxicology, Slovak Academy of Sciences, Dubravska cesta 9, 84104 Bratislava, Slovakia. E-mail: barbara.kaprinay@savba.sk
Metabolic syndrome (MetS) is a cluster of related conditions that increases the risk for developing cardiovascular diseases and type 2 diabetes mellitus. The manifestations of MetS are dyslipidemia, elevated blood pressure, insulin resistance, glucose intolerance, central obesity, atherosclerosis, inflammatory reactions, endothelial dysfunction and prothrombotic state (Grundy et al. 2004, Eckel et al. 2005). Metabolically obese, thus hyperinsulinemic, insulin-resistant, hypertriglyceridemic yet normal-weight individuals are also predisposed to type 2 diabetes and coronary heart disease, comparably to those with evident obesity. Metabolic abnormalities associated with unfavorable lifestyles may lead to consequences of MetS. It is thus lifestyle to identify and treat these individuals before these diseases become overt (Ruderman et al. 1998, Yoon et al. 2007). Increasing attention has been directed toward finding novel strategies to prevent or slow down the onset and/or progression and potentially reverse MetS. Different experimental models of MetS serve as tools for studying the efficacy of these strategies. Some rodent models utilize rats with genetically influenced cardiovascular system, such as spontaneously hypertensive rats (Hulman et al. 1991, de Artinano and Castro 2009). Hereditary hypertriglyceridemic (HTG) rats were described as not obese, hypertensive and insulin resistant and they have some disturbances in glucose metabolism (Zicha et al. 2006). Each of these abnormalities has independently been shown to be associated with impaired aortic endothelial function, as demonstrated by decreased 
endothelium-dependent relaxation (Török et al. 2002). Addition of high fat diet to the food of HTG rats should lead to manifestation of MetS. Thus, the aim of the work was to investigate whether high fat diet administered to Prague hereditary HTG rats can induce signs of MetS.

Experiments were performed on 12 weeks old adult male Wistar (W) and HTG rats. The rats were maintained under a $12 \mathrm{~h}$ light/dark cycle with free access to water and a standard laboratory diet. Animal housing, care and experimental procedures were conducted under the guidelines of the Animal Ethics Committee and were approved by the State Veterinary and Food Administration of the Slovak Republic. HTG rats were divided into two groups: fed standard diet (HTG) and fed high fat diet (HTGch). W rats served as a control group. The high fat diet contained $1 \%$ cholesterol and $7.5 \%$ lard and was given over 8 weeks. At the end of the experiment, preprandial glucose and glucose tolerance test (GTT) was evaluated. Blood pressure was measured by non-invasive method of tail-cuff plethysmography. Levels of blood lipids (triacylglycerols-TAG, total cholesterol - Ch, low density lipoprotein-Ch - LDL-Ch, high density lipoprotein-Ch-HDL-Ch) as well as markers of oxidative stress - concentrations of thiobarbituric acid reactive substances (TBARS) - were determined in the liver according to Esterbauer (1993). The specific activity of lysosomal $\mathrm{N}$-acetyl- $\beta$-D-glucosaminidase (NAGA), a marker of cellular injury, was assayed according to standard methods as described previously in Navarova and Nosalova (1994) in the liver. The endothelium-dependent relaxation of isolated pre-contracted aortic rings induced by acetylcholine was evaluated under isometric conditions (Sotnikova et al. 2013).

During the first week of the experiment, HTGch rats consumed a significantly higher amount of chow $(29.6 \pm 1.1 \mathrm{~g} / \mathrm{rat} /$ day $)$ compared to HTG and
W ( $25.3 \pm 0.9 \mathrm{~g} / \mathrm{rat} /$ day and $26.1 \pm 0.3 \mathrm{~g} / \mathrm{rat} /$ day, resp. $)$. At this time body weight gain of HTGch rats increased significantly (to $115.3 \pm 0.8 \%$ of their initial body weight expressed as $100 \%$ ) compared to HTG and $\mathrm{W}(111.0 \pm 0.9 \%$ and $111.7 \pm 0.8 \%$, resp.). This trend however did not continue further. At the end of the experiment their body weights were: W: $396.3 \pm 0.9 \mathrm{~g}$, HTG: $362.4 \pm 1.5 \mathrm{~g}, \mathrm{HTGch}: 377.2 \pm 1.2 \mathrm{~g}$. The livers of HTGch rats were fatty and gave evidence of developing steatosis. The liver weight was significantly increased in HTGch $(18.2 \pm 0.5 \mathrm{~g})$ compared to both experimental groups with standard diet (HTG: $11.9 \pm 0.3 \mathrm{~g}$; $\mathrm{W}: 11.3 \pm 0.3 \mathrm{~g})$. Preprandial glucose was significantly higher in HTG and HTGch $(5.1 \pm 0.13$ and $5.8 \pm 0.2 \mathrm{mmol} / \mathrm{l}$, resp.), compared to $\mathrm{W}(3.96 \pm 0.1 \mathrm{mmol} / \mathrm{l})$. The glucose tolerance test showed a significant defect in glucose metabolism in HTG and HTGch groups expressed by ongoing increase of glucose level in blood serum $120 \mathrm{~min}$ after intraperitoneal administration of glucose solution $(2 \mathrm{~g} / \mathrm{kg} \quad$ b.w.) to rats (HTG: $9.0 \pm 0.3 \mathrm{mmol} / \mathrm{l}$; HTGch: $8.2 \pm 0.5 \mathrm{mmol} / \mathrm{l})$ compared to $\mathrm{W}$ rats $(3.96 \pm 0.09 \mathrm{mmol} / \mathrm{l})$.

Hypertriglyceridemia participates in the development of atherosclerosis and hypertension in humans. As expected, increased fasting serum levels of TAG were found in HTG compared to W rats (Fig. 1). The HTGch rats had higher levels of TAG compared to $\mathrm{W}$, however these were lower in comparison to HTG (Fig. 1). The reason of this phenomenon is not known and needs to be elucidated. In contrast to serum TAG, high fat diet significantly influenced the serum lipid profile - it increased levels of total $\mathrm{Ch}$ and LDL-Ch in HTGch compared to HTG rats. Decreased levels of HDL-Ch in HTG rats were not further influenced by high fat diet (Fig. 1). All these findings confirmed a dyslipidemic state of HTGch animals. Changes in plasma lipids were accompanied with blood pressure changes. At the
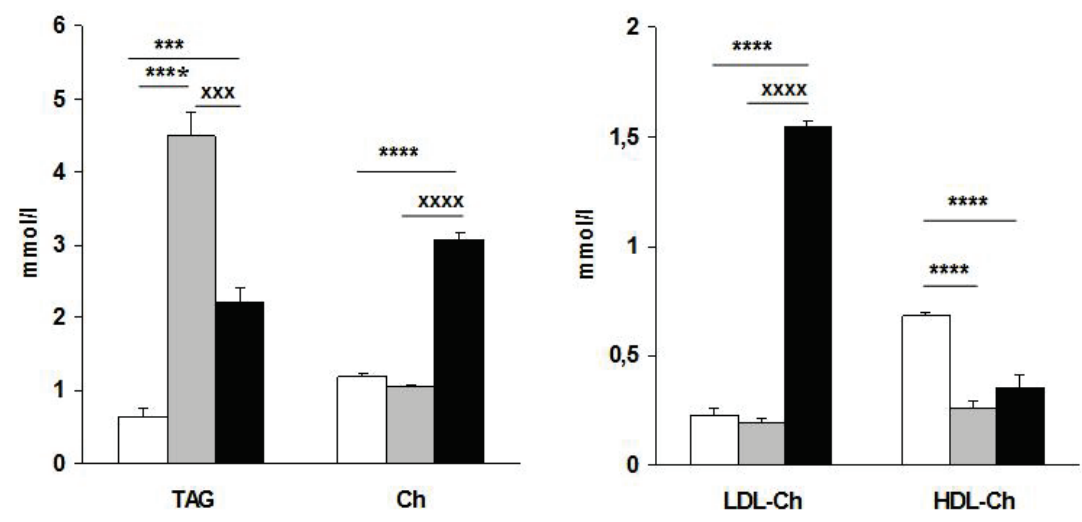

Fig. 1. The lipid profile in serum of Wistar (white columns), HTG (grey columns) and HTGch rats (black columns). TAG - triacylglycerols, Ch - total cholesterol, LDL-Ch - low density lipoprotein cholesterol, HDL-Ch - high density lipoprotein cholesterol. Data are means \pm S.E.M., $n=10 .{ }^{* * *} \mathrm{P}<0.001$ versus $\mathrm{W}$; ${ }_{* * * *} \mathrm{P}<0.0001$ versus $\mathrm{W}$, ${ }^{\mathrm{x} x \mathrm{x}} \mathrm{P}<0.001$ versus HTG; ${ }^{x 00 x} \mathrm{P}<0.0001$ versus $\mathrm{HTG}$. 

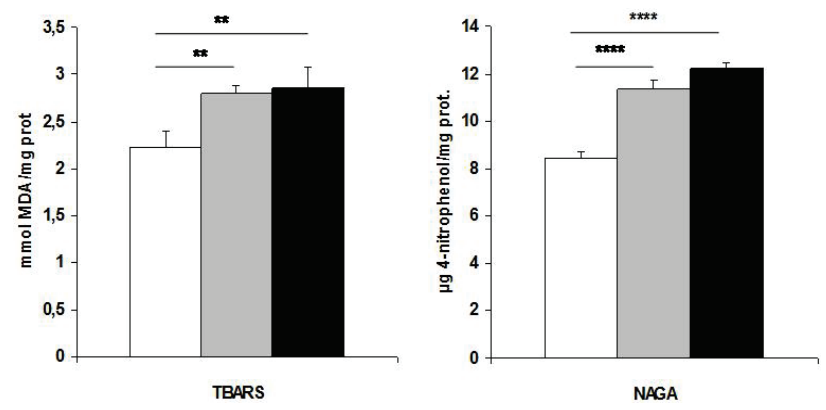

Fig. 2. Markers of oxidative stress in liver of Wistar (white columns), HTG (grey columns) and HTGch rats (black columns). TBARS - thiobarbituric acid reactive substances; MDA - malondialdehyde; NAGA - N-acetyl- $\beta$-D-glucosaminidase. Data are means \pm S.E.M., $n=10 .{ }^{* *} \mathrm{P}<0.01$ versus $\mathrm{W}$, ${ }^{* * * *} \mathrm{P}<0.00001$ versus $\mathrm{W}$.

beginning of our experiment the values of blood pressure were $114.74 \pm 1.9 \mathrm{~mm} \mathrm{Hg}(\mathrm{W}), 118.67 \pm 2.1 \mathrm{~mm} \mathrm{Hg}(\mathrm{HTG})$ and $115.74 \pm 1.5 \mathrm{~mm} \mathrm{Hg}$ (HTGch). After 8 weeks of the experiment, blood pressure of HTG and HTGch $(129.3 \pm 2.5$ and $128.7 \pm 2.5 \mathrm{~mm} \quad \mathrm{Hg}$, resp.) was significantly increased compared to W (113.5 $\pm 2.9 \mathrm{~mm} \mathrm{Hg})$.

MetS is known to be related to aggravated oxidative stress, both in animal models (HernándezSalinas et al. 2015) and in humans (Park et al. 2011). Links between atherosclerosis along with cardiovascular risk and MetS, insulin signaling, oxidative stress and inflammation have been reported (Kim et al. 2013). Our results are in accordance with these findings - increased TBARS levels and increased activity of NAGA in the liver in HTG and HTGch groups indicated the presence of oxidative stress in both groups (Fig. 2).

Endothelial injury and dysfunction is an important initial event in atherogenesis (Xi et al. 2007, Sima et al. 2009). However, contrary to results of Török et al. (2002), we observed only slight reduction in the endotheliumdependent relaxation of the HTG and HTGch aortas (Fig. 3). Thus the function of the endothelium does not seem to be significantly impaired. The endothelial dysfunction leading to impaired vasorelaxation in HTG rats develops in parallel with the progress of hypertension (Zicha et al. 2006). At the beginning of our experiments, HTG rats were still normotensive and their blood pressure increased only after 8 weeks. We thus suppose that endothelial dysfunction

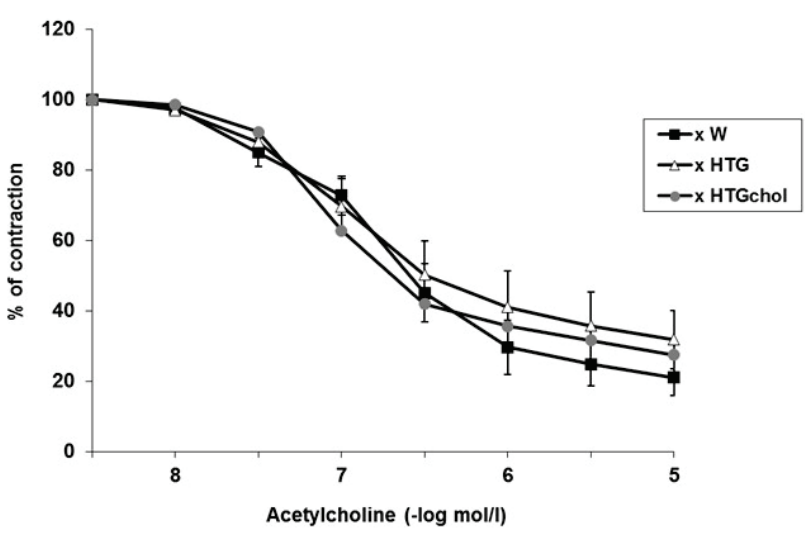

Fig. 3. Endothelium- dependent relaxation to acetylcholine in the isolated aorta of Wistar (black squares), HTG (white triangles) and HTGch (grey circles) rats. Relaxations are expressed in \% of precontraction induced by phenylephrine $\left(10^{-6} \mathrm{~mol} / \mathrm{l}\right)$. Data are means \pm S.E.M., $n=10$.

would manifest with prolonged duration of the experiment.

In summary, non-obese HTGch rats had disturbed glucose and also lipid metabolism - increased serum triacylglycerol, total cholesterol and LDL-Ch levels, decreased HDL-Ch level, and their livers had markers of developing steatosis. Moreover, they had increased blood pressure. All these changes were accompanied with oxidative stress and tissue damage. We assume that the model used may be suitable for the study of MetS with absence of obesity. Prolonging the duration and/or addition of fructose to the high fat diet might have a major impact on all parameters tested, especially on vascular endothelial function.

\section{Conflict of Interest}

There is no conflict of interest.

\section{Acknowledgements}

This study was supported by the VEGA grant No. 2/0054/15. We express our thanks to Mrs. Dytrichova, Srnova and Vandakova for their skillful technical assistance. We appreciate a goodwill of Ludmila Kazdova, $\mathrm{PhD}$. from Institute for Clinical and Experimental Medicine, Prague, Czech Republic, who donates us a breeding core of hereditary hypertriglyceridemic rats.

\section{References}

DE ARTINANO A, CASTRO MM: Experimental rat models to study the metabolic syndrome. $\mathrm{Br} J$ Nutr 102: 1246-1253, 2009.

ECKEL RH, GRUNDY SM, ZIMMET PZ: The metabolic syndrome. Lancet 365: 1415-1428, 2005. 
ESTERBAUER H: Cytotoxicity and genotoxicity of lipid-oxidation products. Am J Clin Nutr 57: 779-785, 1993.

GRUNDY SM, HANSEN B, SMITH JR SC, CLEEMAN JI, KAHN RA: Clinical management of metabolic syndrome: report of the American Heart Association/National Heart, Lung, and Blood Institute/American Diabetes Association Conference on Scientific Issues Related to Management. Circulation 109: 551-556, 2004.

HERNÁNDEZ-SALINAS R, DECAP V, LEGUINA A, CÁCERES P, PEREZ D, URQUIAGA I, ITURRIAGA R, VELARDE V: Antioxidant and anti-hyperglycemic role of wine grape powder in rats fed with a high fructose diet. Biol Res 48: 53, 2015.

HULMAN S, FALKNER B, CHEN YQ: Insulin resistance in the spontaneously hypertensive rat. Metabolism 40: 359-361, 1991.

KIM M, PAIK JK, KANG R, KIM SY, LEE SH, LEE JH: Increased oxidative stress in normal-weight postmenopausal women with metabolic syndrome compared with metabolically healthy overweight/obese individuals. Metabolism 62: 554-560, 2013.

NAVAROVA J, NOSALOVA V: Effect of H2-receptor antagonists on indomethacin-induced lysosomal enzyme release from rat gastric mucosa. Methods Find Exp Clin Pharmacol 16: 119-124, 1994.

PARK SH, KIM JY, LEE JH, PARK HY: Elevated oxidized low-density lipoprotein concentrations in postmenopausal women with the metabolic syndrome. Clin Chim Acta 412: 435-440, 2011.

RUDERMAN N, CHISHOLM D, PI-SUNYER X, SCHNEIDER S. The metabolically obese, normal-weight individual revisited. Diabetes 47: 699-713, 1998.

SIMA AV, STANCU CS, SIMIONESCU M: Vascular endothelium in atherosclerosis. Cell Tissue Res 335: 191-203, 2009.

SOTNIKOVA R, OKRUHLICOVA L, VLKOVICOVA J, NAVAROVA J, GAJDACOVA B, PIVACKOVA L, FIALOVA S, KRENEK P: Rosmarinic acid administration attenuates diabetes-induced vascular dysfunction of the rat aorta. $J$ Pharm Pharmacol 65: 713-723, 2013.

TÖRÖK J, BABÁL P, MATUŠKOVÁ J, LUPTÁK I, KLIMEŠ I, ŠIMKO F: Impaired endothelial function of thoracic aorta in hereditary hypertriglyceridemic rats. Ann N Y Acad Sci 967: 469-475, 2002.

XI H, AKISHITA M, NAGAI K, YU W, HASEGAWA H, ETO M, KOZAKI K, TOBA K: Potent free radical scavenger, edaravone, suppresses oxidative stress-induced endothelial damage and early atherosclerosis. Atherosclerosis 191: 281-289, 2007.

YOON YS, LEE ES, PARK C, LEE S, OH SW: The new definition of metabolic syndrome by the international diabetes federation is less likely to identify metabolically abnormal but non-obese individuals than the definition by the revised national cholesterol education program: The Korea NHANES Study. Int $J$ Obes 31: 528-534, 2007.

ZICHA J, PECHANOVA O, CACANYIOVA S, CEBOVA M, KRISTEK F, TÖRÖK J, SIMKO F, DOBESOVA Z, KUNES J: Hereditary hypertriglyceridemic rat: a suitable model of cardiovascular disease and metabolic syndrome? Physiol Res 55: 49-63, 2006. 